Masuma H. Mammadova ${ }^{1,2}$, Zarifa G. Jabrayilova ${ }^{3}$, Faig R. Mammadzadeh ${ }^{3}$

DOI: $10.25045 /$ jpit.v07.i2.11

Institute of Information Technology of ANAS, Baku, Azerbaijan

${ }^{1}$ masuma.huseyn@iit.ab.az, ${ }^{2}$ mmg51@mail.ru, ${ }^{3}$ depart15 @iit.ab.az

\title{
SUPPLY AND DEMAND IN IT-SEGMENT OF AZERBAIJAN LABOR MARKET
}

In this paper, the state of the art situation in the sphere of IT personnel implementation is considered on the basis of the monitoring results of supply and demand in IT-segment of Azerbaijan Labor Market. The problems, reasoning mismatch between the supply and demand on the labor market are displayed. Supply and demand in the IT-segment of labor market from the positions of It-specialists, employers and experts are analyzed. Inflow and outflow of IT-specialists are researched, and the evaluation of IT-specialists who have changed activity field is given.

Keywords: IT-segment of labor market, supply and demand, sociological poll, outflow of IT-specialists.

\section{Introduction}

The special role of ICT in the development of both, global and national economies, to accelerate the transition process, based on knowledge, is generally recognized. The penetration of ICT in various spheres of human activity and the transformation of information into a global resource resulted in sharply increased labor market demand for specialists in information technology (IT) professionals. For example, today, deficit of IT professionals is observed in almost all 27 EU countries [1-3]. Experts predict that the number of IT jobs by 2020 could increase from 750000 to 1 million compared to 274 000 in 2013, and this happens against the backdrop of reducing the number of persons receiving European higher IT profile, engineering and natural sciences education. The growing demand for IT professionals and the inadequate supply is observed in the developed countries such as the US and Canada [4, 5]. The CIS countries, including Azerbaijan, also face with the problem of disparity between the IT professionals demand and supply [6-9].

\section{Problems of mismatch of supply and demand in the IT professionals labor market.}

Currently, the labor and the education market have different mechanisms and timing functions. While the education system is developed on the basis of long-term policies and strategies, the IT industry must adapt to rapidly changing market demands and technological innovation in order to remain competitive in the global, national and local markets [10-12]. With this in mind, many countries are in favor of political initiatives aimed at the development of new technologies and tools to regulate supply and demand of IT professionals. Measures such as standardization of competence models, working with employers and relevant professional IT sector educational standards, the expansion of admission to specialized IT departments, to a certain extent, promote the convergence of labor markets and IT education, but both areas continue to function in parallel [13-16].

In Azerbaijan, the issues of reducing the mismatch of supply and demand in the labor market, moreover, in staffing IT segment are also of great significance. Being one of the priority sectors of the economy the information and communication technologies (ICT) and the formation of national policy in this area have stimulated the expansion and deepening of IT applications, and have caused sharply increasing demand for IT professionals. This, in turn, has actualized the problem of staffing the IT industry and the need for political decision-making, promoting the harmonization of supply and demand for IT professionals. The issues of various political documents receive attention. Hence, in the "National Strategy for Information Society Development in Azerbaijan Republic for 2014-2020" [17] on the training of qualified personnel able to produce globally competitive high-tech products and services are given special attention. The Strategy declared that improving the competitiveness of the country and the expansion of the ICT industry's export potential associated primarily with the formation of the corresponding human potential. Here, training highly skilled IT personnel at various 
levels of education is linked to the development of the ICT sector. Systematic updating and bringing IT education in line with market requirements, and increased research training on innovative areas of ICT are the main priorities of the staffing industry.

In this regard, special significance today acquire analysis of various models of two-way communication of the education system and labor market and development, taking into account the context of the country's national model, which is mostly conducive to the relevant improvement of the education system (offers) demand on the labor market, on the one hand, and the system forming request on staff with specific qualifications, - on the other.

For the IT professionals labor market it is specific the complexity of the acquisition of reliable information about its condition and contradictory data stream, forming supply and demand. On the one hand, the lack of official data on the supply and demand for IT professionals connected to the imperfection of methods of collecting statistics in this area, and on the other hand, the difficulty of obtaining accurate information because of the opacity of the IT companies, does not allow to adequately acquire the initial description of ICT sector status, quantitatively based only on empirically measurable indicators. As far as the qualitative aspects of the supply and demand are concerned, their evaluation is possible only on the expert estimations' basis. Thus, the need for alternative research methods, based on questionnaires, increases.

The World practice of studying the demand and the ICT industry offers shows that, for a long time, in many countries, there are special structures (centers, institutes) engaged in systematic collection and analysis of qualitative and quantitative indicators of the IT professionals' labor market. The use of primary and secondary information sources contributes significantly to the creation of the most complete description of the ICT industry development trends.

Taking into account the world practice, the research group of the Institute of Information Technologies of ANAS, which includes the authors of this article, the decision was made to obtain initial information about the state of demand and supply in the labor market of IT professionals to initiate a sociological study. The main goal of the sociological labor market research in the field of information technology was to identify the IT professionals' situation in the field of staffing of the IT industry through the prism of demand and supply in the labor market. At the same time, to assess the quantitative indicators of supply and demand of the IT industry is used as a data from secondary sources; the State Statistics Committee of Azerbaijan Republic (AR), the Ministry of Education of Azerbaijan and the State Students Admission Commission.

The monitoring of labor market of IT professionals in Azerbaijan held for the first time in 2008, by the Institute of Information Technologies allowed to respond to a number of urgent issues [6]. Analysis of the current situation in the field of continuous vocational training in the country revealed that the education provided in the field of IT partially solves the mismatch problem of skills. Therefore, IT specialized education lags behind the development of the IT sector in the country, and is not able to produce IT professionals that meet the requirements of the labor market not only quantitatively, but also quality obtained professional knowledge and skills. Although, basic training is not satisfactory, the systematic introduction of new technologies, software platforms and methodologies for solving IT problems leads to a drastic reduction of the life cycle of modern information technology and obtained IT knowledge and skills. At the same time, this leads to corresponding changes in the labor market (employers) to professional and quality characteristics of IT specialists. This, in turn, updates the task of systematically updating the content of IT training curricula in the formal education system and in the framework of a continuous training [18-20].

Further, results of the survey [9] shows that today the Azerbaijani labor market is still not filled with demanded staff. We can specify the indicators of the demand for skilled IT professionals as follows: 1) the lack of skills in certain IT professions and specialties, it is difficult to fill vacancies (qualitative indicators); 2) employment of the persons in IT jobs, the actual structure of specialties of whose refers to the related industries; 3) employment of staff units on information technology by the students and representatives of other professions and occupations, often far from IT. It is expected that 
with the increase in demand for IT specialists, the number of non-core professionals will also increase from the supply perspective of IT professionals, and on the contrary, the decline in demand for IT professionals will reduce employers' willingness to hire the specialists from other fields of activity in IT-oriented jobs.

In 2014, the Institute of Information Technologies conducted a second study of the labor market of IT professionals. The aim of the next study was to identify the current situation on staffing, the IT sector both from the standpoint of demand (employers) and supply (staff training), carrying out a comparative analysis of the results of two surveys on key labor market indicators, identifying the trends observed in the sector in the context of the structure of specialties and requirements to knowledge and skills of IT professionals, as well as, identifying the degree of saturation of the market of IT specialists and assessing the proportion of non-core professionals working in the IT positions.

Another quite challenging task of evaluating the human resources of the IT industry is the identification of IT professionals, who changed the scope of professional activity. International practice shows that the identification of the number of IT professionals, who changed the scope of professional activity, including those who retired, is a rather difficult task, and it is difficult to be practically implemented [21]. Currently, among the European countries, only the Netherlands and Ireland identified this information. With that view, on a specific methodology ROA (Research Centre for Education and the Labour Market, founded in 1986) at Maastricht University in the Netherlands annually holds a survey of graduates who graduated one and half year ago [22]. In Ireland, the Expert Group on Forecasting for skilled labor demand, established in 1997, carried out the monitoring of the further activity of graduates with a personal unique identifier [23]. The authors attempted to estimate the proportion of IT professionals who had changed the professional activity. To this end, in November 2015, we conducted a survey of a number of IT graduates of relevant departments of Azerbaijani universities. The purpose of the study was to establish feedback with the IT-specialized education graduates, the identification of information on their respective areas of current activity of the specialty obtained in high school, and the identification of the reasons for the transition of IT graduates to other areas, and assessment of the proportion of the outflow of IT specialists in other areas of activity.

Taking into account the limitations on the scope, this article highlights only a few of the abovementioned two studies, which mainly involve qualitative aspects of the supply and demand for IT professionals.

\section{Analysis of supply and demand in the labor market of IT professionals}

The implementation of the second case study is based on the methodology proposed for the implementation of the first survey [6,24]. Data sources of research to identify the status of the market of IT professionals, its dynamics and development prospects, includes the sample population consisted of the three types of respondents: 1) IT specialists (basic sample); 2) IT experts; and 3) employers, submitted by business entities of all forms of ownership relying on IT profile. Unlike the first study, the sample size of the second survey is much more representative. Thus, the total sample covers 2350 respondents (60.6\% - men, 39.4\% - women), including 2,017 respondents, who work as IT specialists, 146 employers and 187 experts. The main sample is determined on the basis of the cluster sampling method. It consists of homogeneous (similar) groups, distributed by regions as the country and the main areas of the economy, which makes it possible to some extent to ensure the representativeness of the data.

The survey of the respondents, who work as IT professionals, both in the capital and the regions of Azerbaijan, revealed that the vast majority of them (84.9\%) have a university degree (Figure 1 ).

Increasing the demand for IT professionals, and the relatively high level of wages of the latter can cause the transition of specialists to other strategically important sectors of economy in the sphere of information technologies. This fact is reflected in the responses of IT professionals on the issue of the specialty that they have acquired in the universities. For example, among those working as IT professionals, $58.5 \%$ are IT specialized education; $15.7 \%$ are the graduates of potentially close IT specialties (Physical and Mathematical, Engineering and Technological); 26.2\% of respondents hold 
a university diploma with specialties that are completely unrelated to IT (Biologist, Lawyer, Journalist, Economist, Architect, Chemist, etc.).

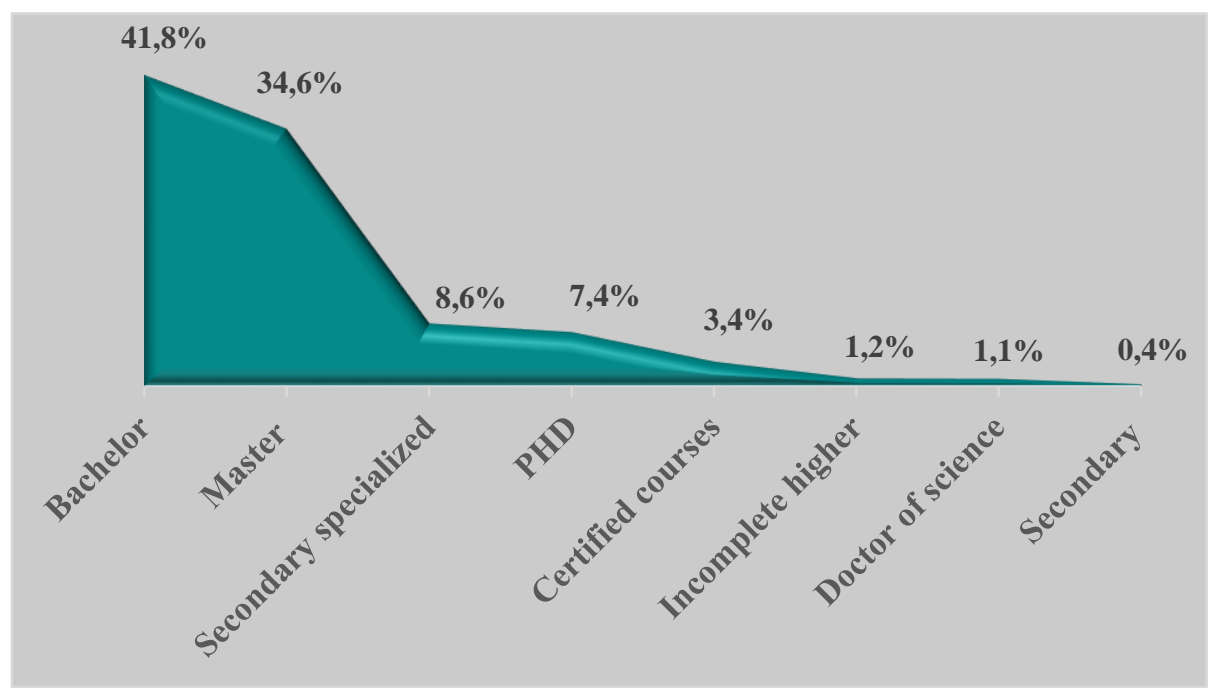

Figure 1. Education Background of Respondents

This means that more than a quarter of the respondents participating in the survey as IT professionals have a basic education in the fields, absolutely far from information technology. According to the first survey (2008), the share of these categories were, $45 \%, 29 \%$ and $26 \%$, respectively. Comparative analysis of the results of the two surveys shows a steady flow in the IT specialists from other fields of activity. The presence of such situation is alarming, since, on the one hand, it may reflect a shortage of IT professionals, and on the other hand, be an indicator of the IT professionals' transition to other specialties. Therefore, from our point of view, to identify the causes of the observed situation, additional research is required.

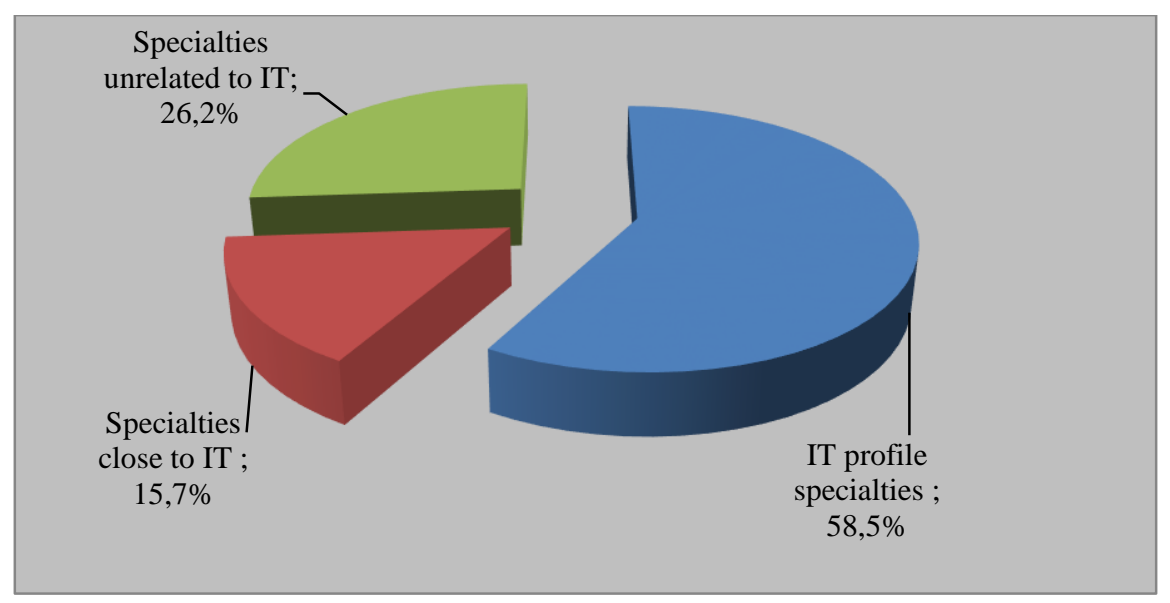

Figure 2. Distribution of respondents according to the profile of the specialty acquired at universities

The correlation between the period of study in high school respondents to the received specialty reveals an interesting picture. Therefore, as can be seen from Figure 3, while in 19601980 the deficit of IT professionals was covered primarily due to potentially close to the IT specialties, in subsequent years, there is a tendency to an increase in compensation for the lack of the latter at the expense of graduates of non-core disciplines. 


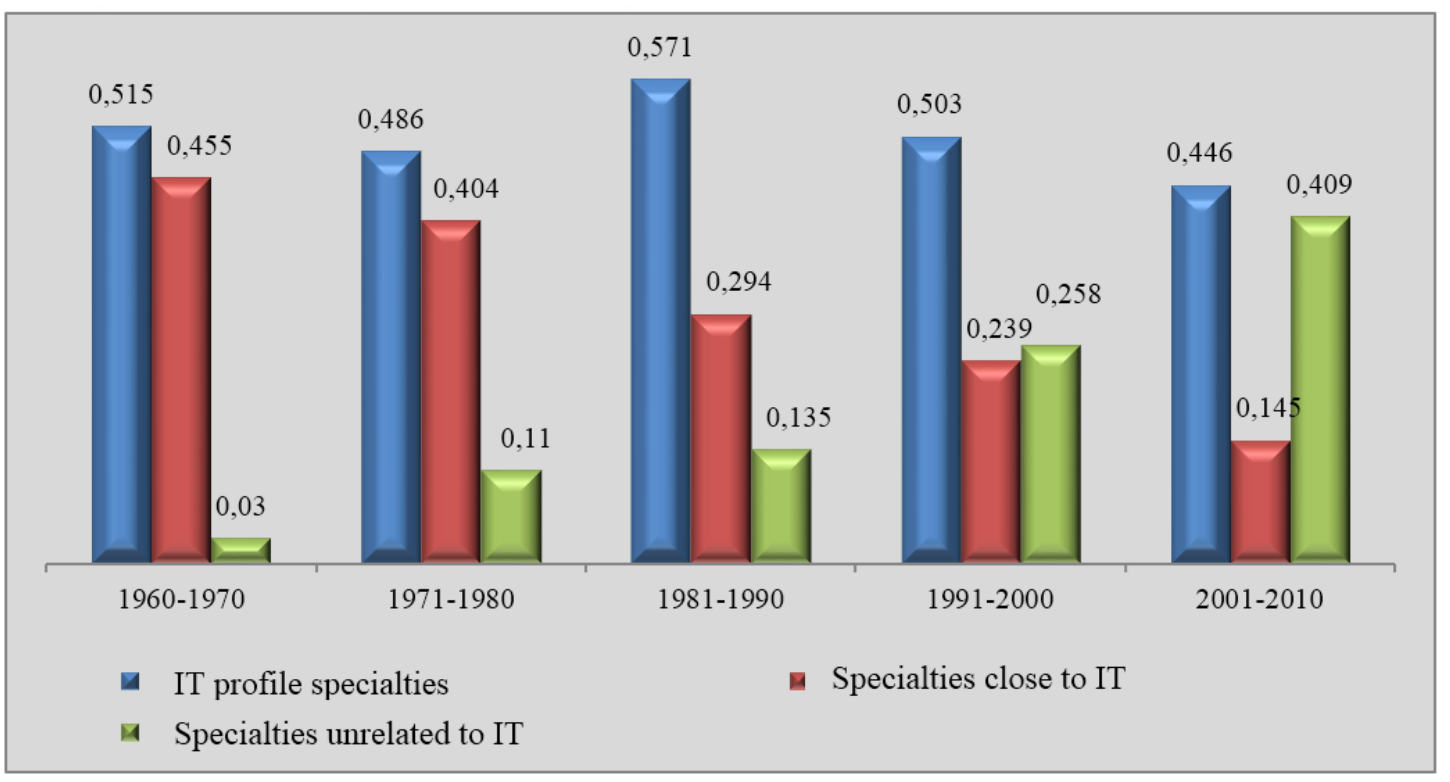

Figure 3. Distribution of respondents according to their specialty profile

\section{Evaluation of IT education IT professionals}

The characteristic of IT education pursued by IT specialists evokes great interest. $22.5 \%$ of respondents, when assessing the quality of IT education in the educational institutions, who did not completed (or are continuing) their education, believe that the preference is mainly given to theoretical training. The overall picture of the survey results on this issue, as reflected in Figure 4, shows that nearly half of IT professionals $(49.1 \%=23.2 \%+18.8 \%+7.1 \%)$ are satisfied with the quality of the received education. At the same time, the responses were diverse, both when assessing the levels of theoretical and practical training, as well as when assessing the quality of study programs.

Along with the problems taking place in the IT education, $53.5 \%$ of respondents in terms of labor market requirements to assess their specialty is high enough, $42.1 \%$ - assess it with low score, only a small proportion of respondents $-4.4 \%$ consider their specialty unpromising. This is natural, because the educational and intellectual level of the subjects of study are different and not all students are equally master the knowledge and skills in the learning process: both very talented and with an average level of training and fairly weak capabilities are among them, which further reflected in the positions they occupy, career development, attitudes, etc. The factor of motivating the specialty choice is also important.

From the point of identifying the compliance of obtained education with the requirements of the institution, which employs IT specialists, the majority of respondents (43.8\%) reported full compliance. Further, $28.7 \%$ of IT professionals believe that the obtained education partially meets the requirements of the institution, $17.3 \%$ of respondents see the weak compliance, and $10.2 \%$ evaluate the level of preparation of the application and the availability of work experience fairly low. According to $67.9 \%$ of IT professionals, practical experience increases the chances of employment, so they are positive about the possibility of work and the acquisition of practical skills from the universities, and $40.2 \%$ of IT experts noted the need for self-replenishment of knowledge and skills, which were not obtained.

Analysis of the degree of compliance obtained the knowledge and skills by IT professionals with the requirements of the institutions, in which they work, through the prism of their form of ownership, shows that most of the respondents (73.1\%), who chose the option "full compliance", were employed in public institutions for the first time.

The fact that, today, against the background of the average wage in the labor market in the IT sector, in the majority of public institutions, especially in the research fields, the wage of IT specialist is quite low, and the possibility of promoting the professionals is limited, and will definitely affect the distribution of recruitment of IT professionals. Thus, currently the hiring students or graduates with little or no experience to such work often by most public institutions, 
and the costs of their efforts to "studying up" are common.

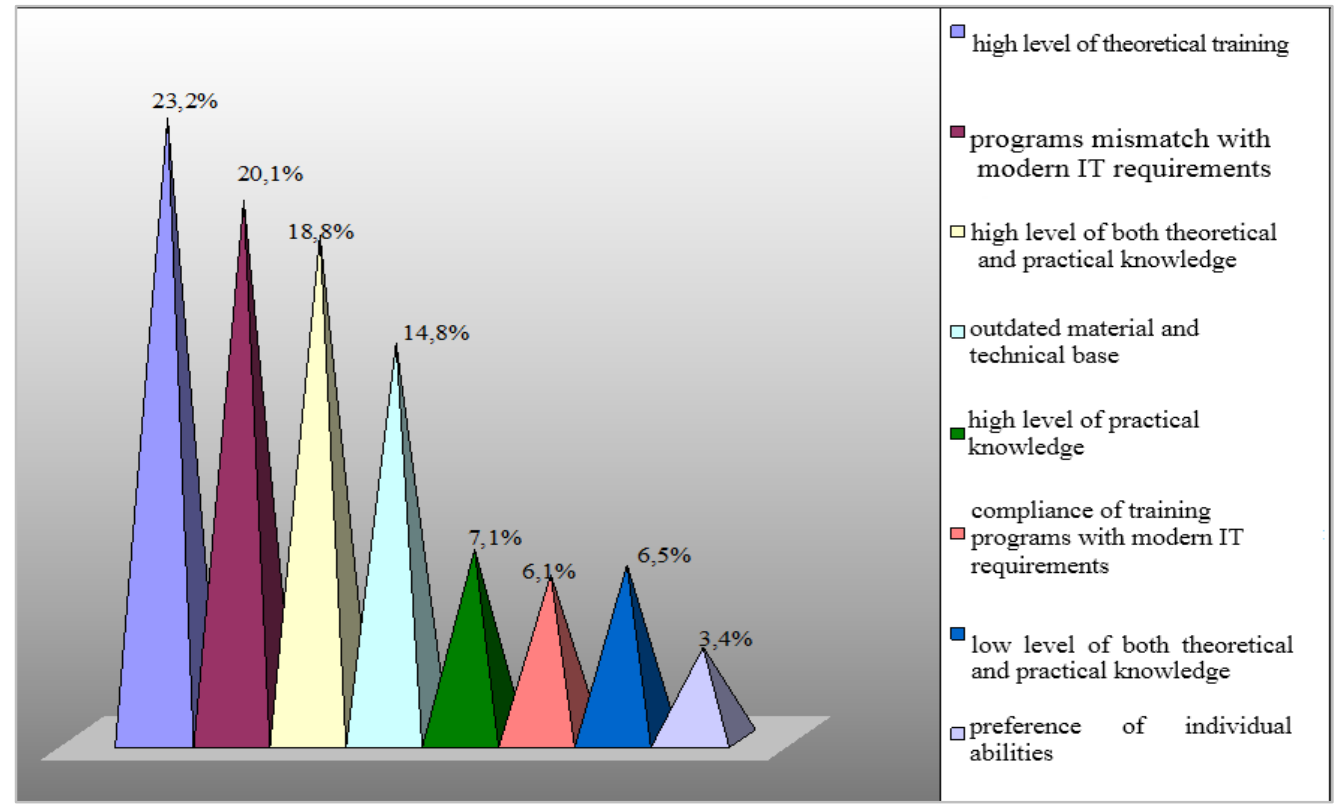

Figure 4. Characteristics of IT education received by IT professionals at universities

This category of IT professionals, who are interested primarily in the admission of a real working environment and improvement of professional skills, agrees to work for the small salary, which is now provided in the staffing of public institutions, temporarily filling existing vacancies. Figure 5 list of ranked 2017 respondents participated in the survey working as IT professionals.

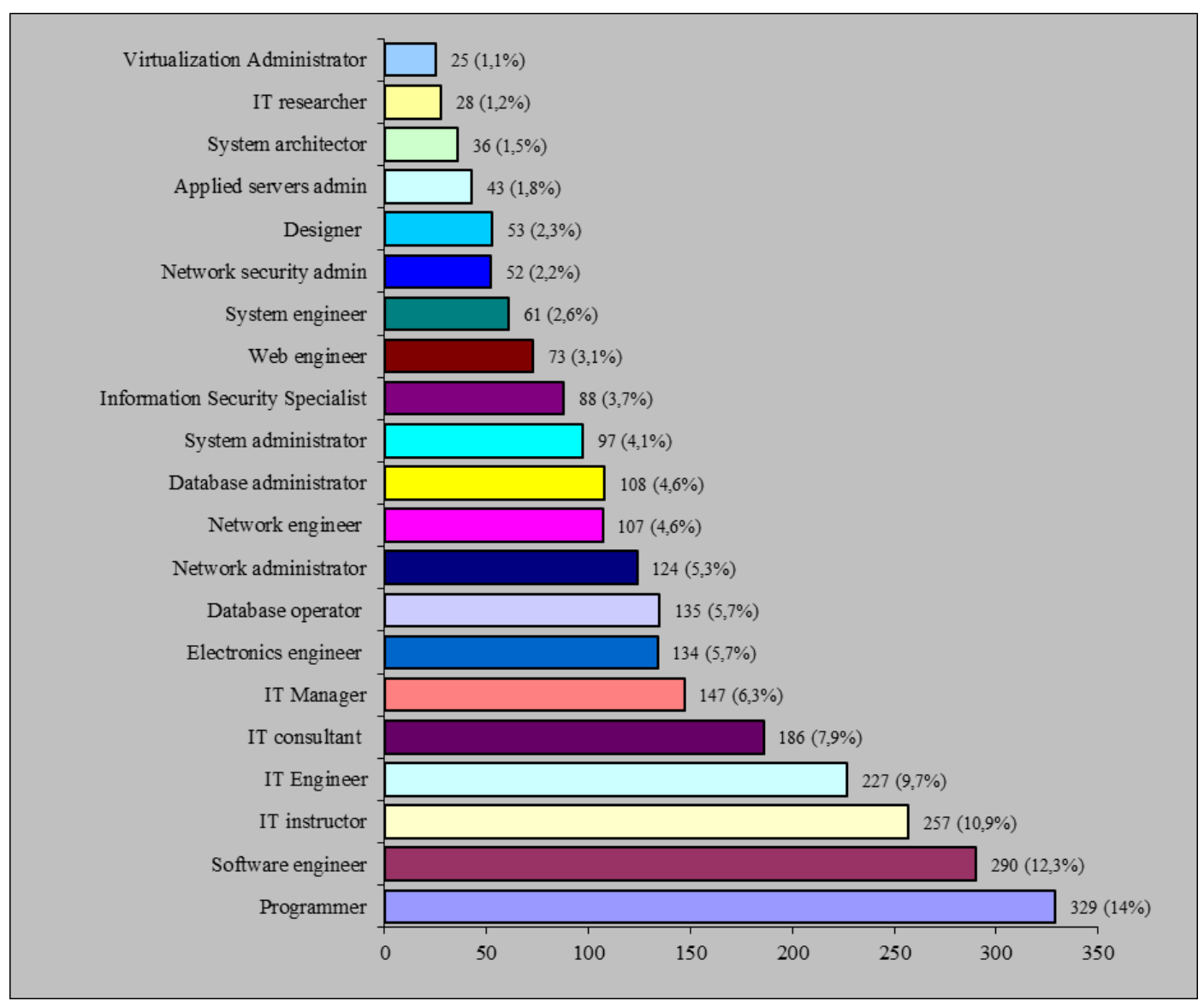

Figure 5. Distribution of respondents according to their present positions 


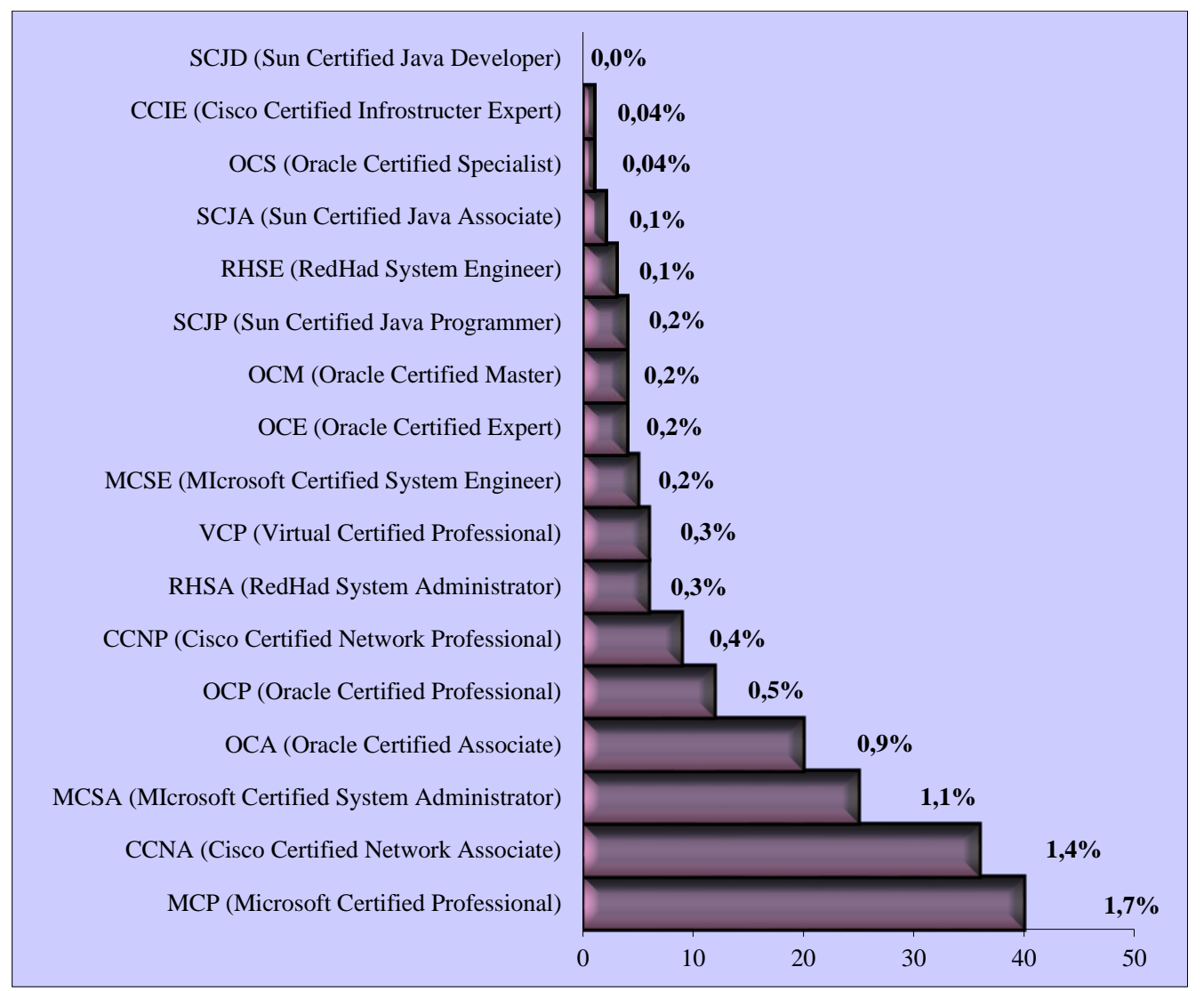

Figure 6. Distribution of the respondents according to their certificates

\section{Evaluation of IT education by employers and experts}

The analysis of the responses of employers and experts interviewed in relation to the quality of training of IT personnel education system introduces the following picture (Figure 7):

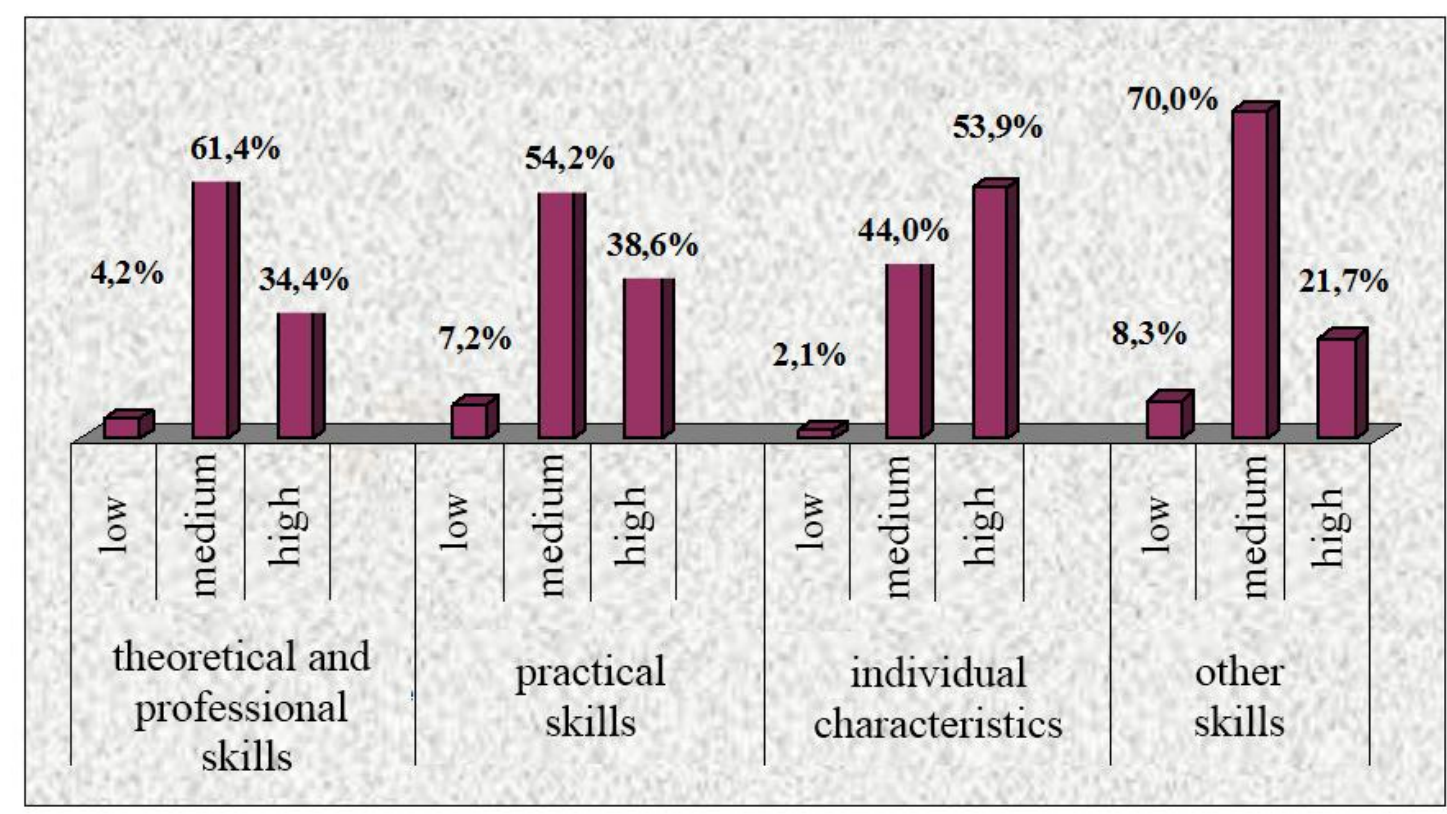

Figure 7. Evaluation of the quality of IT personnel training at education system by employers and IT experts 
Generalized analysis of the responses of employers and experts for the quality of IT education shows that the majority of them assessed the level of training of IT graduates as medium. It actualizes the problem of the adequacy of IT education to the labor market (employers).

These responses are consistent with the views of IT professionals and students on the need for self-replenishment of applied knowledge, which they did not gain. Enterprises and companies (including IT profile), which hire young professionals, have to complete their education at workplace, which requires significant financial and time costs. According to experts, even graduates of specialized universities have to be further educated for at least 6 months after coming to work, and for other specialties, the costs of "adjustment" are even more.

Analysis of the responses to the question about the causes that negatively affect the preparation of educational institutions IT professionals, relevant to the labor market, showed that $23.8 \%$ of employers and IT experts see outdated curricula and material and technical base as a reason. Indeed, today, at most Azerbaijani universities, Pascal, and $\mathrm{C}++$ are leading among the taught programming languages, whereas modern software platforms are taught only at some universities. Further, $22.7 \%$ of respondents indicate that the isolation of knowledge and skills provided in higher education institutions, the real working environment, i.e., labor market needs create obstacles to employment; $20.6 \%$ say that the limited possibility of students to gain practice, so that the latter cannot acquire applied knowledge and specific skills; $17.5 \%$ state that low skill levels of many teachers, often caused by the aging of both the teachers and their knowledge and skills; $15.4 \%$ pay attention to the unsatisfactory level of wages in the educational institutions and, accordingly, the lack of incentives for systematic "self-education" experts in the field of IT.

As an important way out of this situation, the strengthening of the social partnership of education and IT industry can be pointed again. The positive trends observed in recent years in relations between universities and the IT industry should also be noted, which is reflected in the responses of IT experts and employers of IT companies and comparing the results of two surveys. Thus, $68.8 \%$ (compared to $64 \%$ according to the first survey), employers and experts consider it appropriate to establish a direct link with IT profile educational institutions. This is quite an encouraging result, which once again confirms the relevance of taking into account the requirements of the labor market in the education system through the active participation of employers in the educational processes. Most employers - 79.1\% (according to the survey of $2008-78 \%$ ) expressed their interest in participating in the processes of planning and training and production of IT professions programs in which they are interested, that reflects the awareness of the importance of direct participation of representatives of IT industry in personnel training for the industry.

Naturally, the training of qualified specialists for such a dynamic sector like information technology requires direct cooperation between education and employers, one of the areas of which may be the last opportunity to provide students to pass an industrial practice. According to the survey 54.8\% (against 51.5\% - 2008 data) surveyed employers and experts reacted positively to the question of admission of students for practical training on relevant areas of IT; $39.1 \%$ (according to the first survey $-36.5 \%$ ) indicated the presence of both interest and opportunities.

The results of the research requirements of employers and IT experts to the diploma of education showed that the majority of experts $(51.9 \%)$, when receiving a specialist to IT vacancy, the presence of the diploma of physics and mathematics, engineering and IT is considered mandatory; $29.5 \%$ of them give preference to the Diploma of IT-profile education; for $18.6 \%$ - the specialization does not matter. The responses are fully correlated with the current situation on the labor market of IT professionals since "narrowing" of 
requirements can contribute to further growth of unsatisfied demand for IT professionals. Moreover, the widespread application of IT in various sectors of the national economy and the need to address specific problems are often the stimulus for employment in the IT industry with a specialist company formation (economic, biological, and so on.).

Another aspect of the requirements of employers and experts to IT professionals is an individual (personal) quality of the latter. First of all, based on the expert's survey the indicators such as performing discipline, initiative, experience transfer, teamwork and the ability to selfeducation (personal growth) are identified as personal qualities. Distribution of the requirements of employers and experts on these personal characteristics are illustrated in figure.

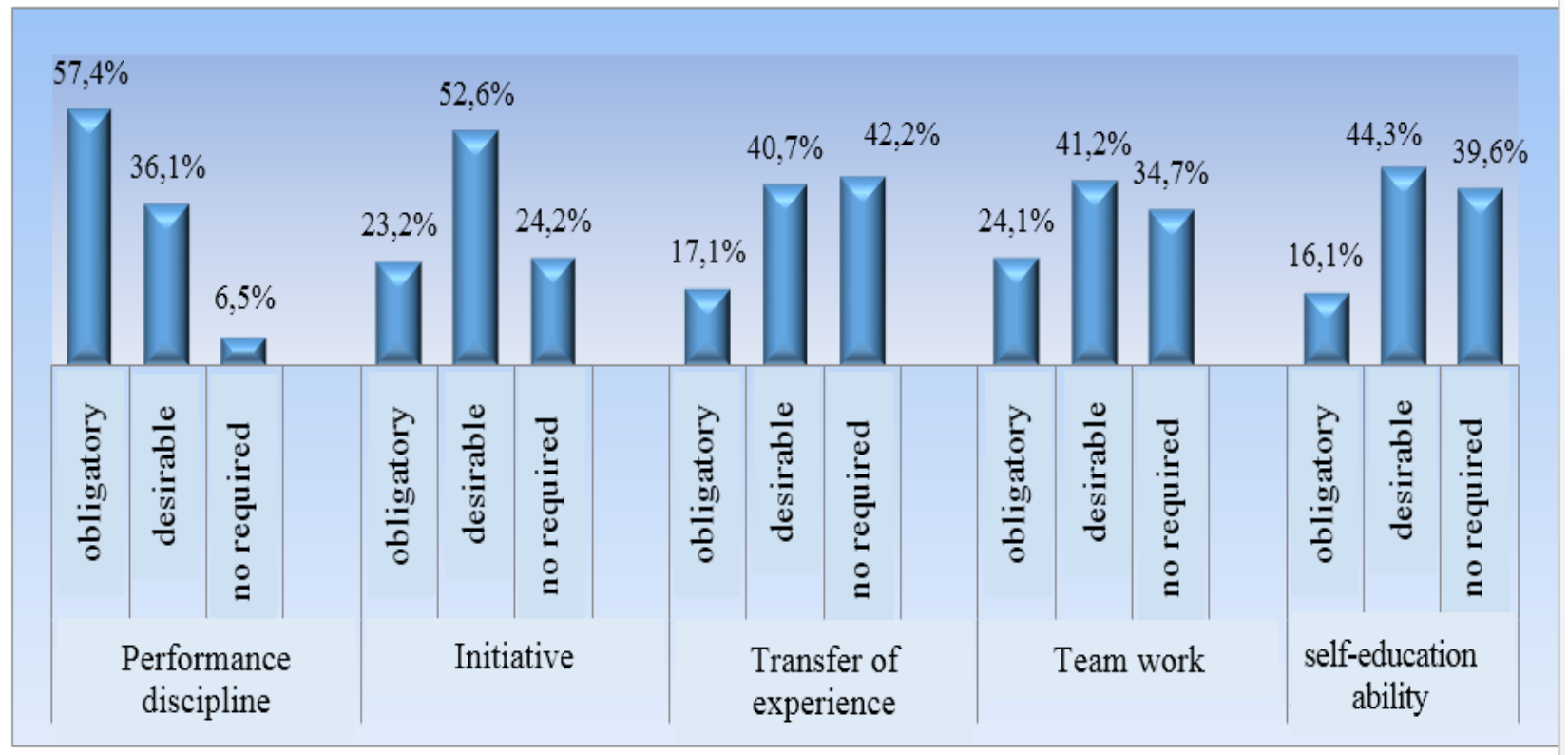

Figure 8. Requirements of employers and experts to the personal qualities of IT professionals

IT professionals are increasingly required the acquisition of specific knowledge beyond their technical competence, requirements for work experience in a similar position, including foreign companies.

The presence of professional certificates, vast horizons in the field of new technologies, knowledge of a foreign language is increasingly becoming important. This is due to the fact that the modern IT professional has to solve the problems that lie at the intersection of information technology and various areas of activity, i.e., carry out their activities at the interface of the program and subject areas in which you want the best information resources management (economy, education, social security, tax area, Customs, etc.).

Some employers, in terms of the nature of the activities, put forward additional requirements to IT professionals, related to both the specific professional knowledge and skills, as well as some personal data. The greatest interest among the additional requirements to IT professionals are accounted for the indicators characterizing the level of professional qualifications of the latter: 1) the availability of certificates of attendance-known companies that are producers of a particular product; 2) work experience in foreign companies; 3) Knowledge of a foreign language. These indicators are, on the one hand, the desire to characterize the IT specialist for professional growth, and on the other - expanding career prospects. Figure 9 reflects the ranking of these requirements for employers and experts by their importance. 
International certificates of Microsoft, Microsoft Navision 1C, Cisco, Cobit, Dell, Ericsson, HP, IBM, Novell, Oracle, SAP, Siebel, SUN Microsystems, and UNIX are very popular among employers and experts.

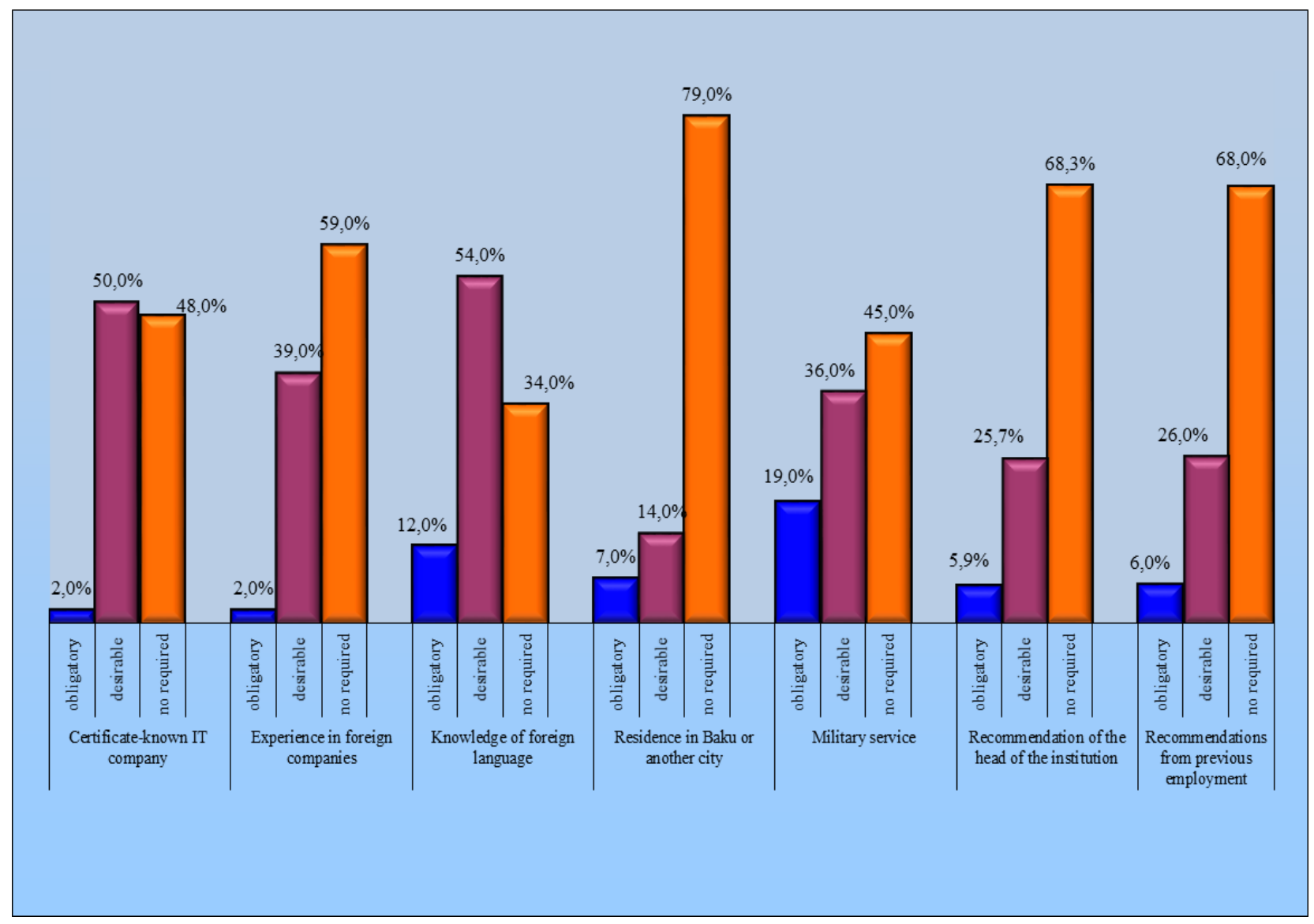

Figure 9. Additional employer's requirements to IT professionals

The responses of employers and experts on the demand for professional specialization of IT professionals in their organizations and companies in accordance with the position sets presented by the experts are of great interest (Figure 10).

According to the ranked demand for a list of IT professions and specializations, today, in the labor market of IT professionals the programmers, software engineers, operating engineers of computer systems, etc. are demanded most. Demand for software engineers is associated not only with their professional programming skills, but with their abilities and skills to develop modern software products and platforms (SAP, Oracle, SQL etc.), their implementation, adaptation and maintenance. 


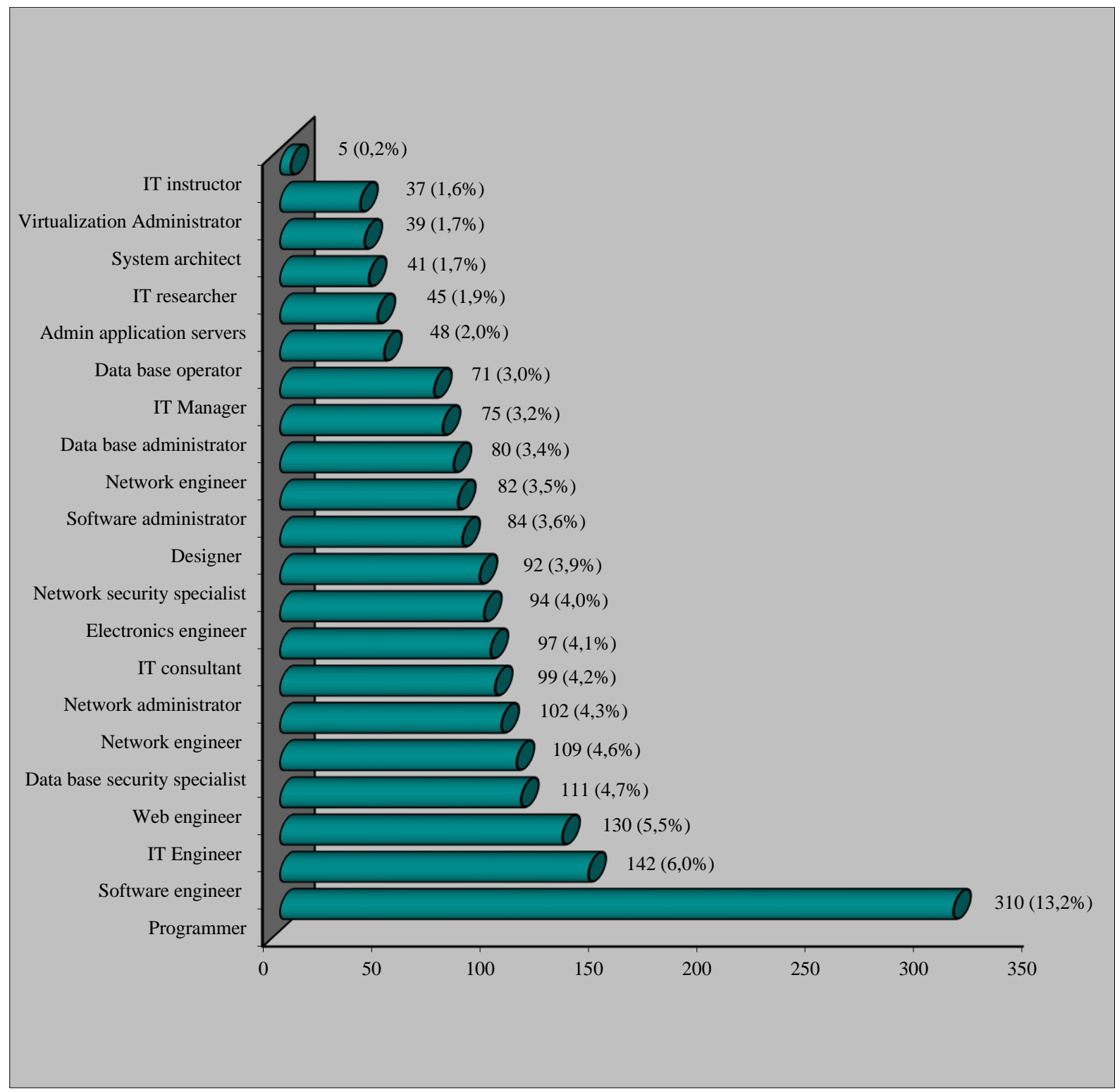

Figure 10. Ranked list of IT professions and specializations, most required by the employers' position

\section{Evaluation of outflow of IT professionals from the industry}

According to the results of the two studies, it was shown a worrying situation on the inflow in the IT professionals industry with basic education in this field, far from the information technology (Figure 2). Whereas, the existence of scarcity of IT professionals is pointed out as one of the assumptions about the causes of this situation, another suggestion is the possible outflow of IT professionals from the industry. To test this hypothesis, a new study was carried out in November 2015. The essence of the latter was to ensure that from to find out how the scope of the graduates' current activities corresponds to the specialty acquired in college by their feedback, and to estimate the proportion of the outflow of IT professionals into other fields.

For this purpose, it was conducted a sociological survey among the graduates of IT-oriented departments of a number of higher educational institutions of Azerbaijan: Baku State University (BSU), Azerbaijan State University of Oil and Industry (ASUOI), Azerbaijan Technical University 
(AzTU) and Azerbaijan University of Architecture and Construction (AzUAC) ( Figure 11) by the specialty groups, indicated in the figure 12 .

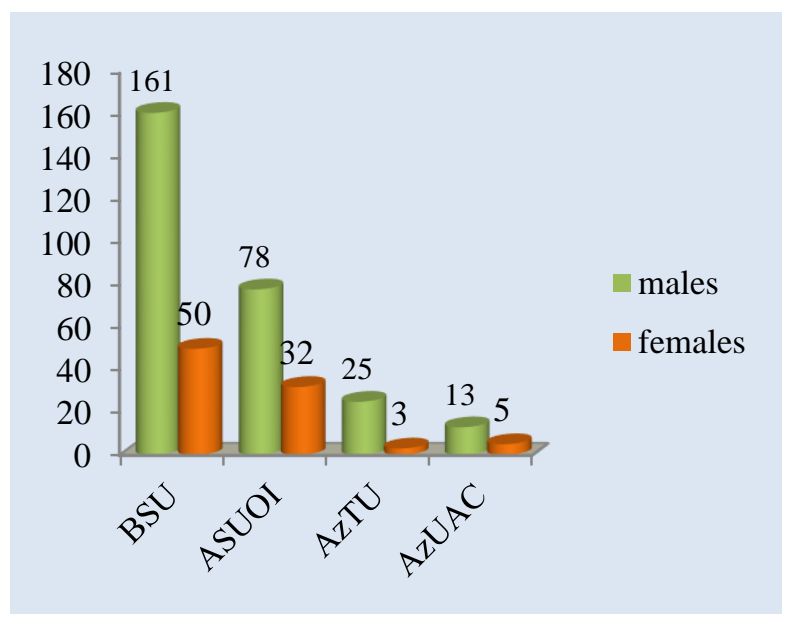

Figure 11. Quantitative distribution of graduates by the universities

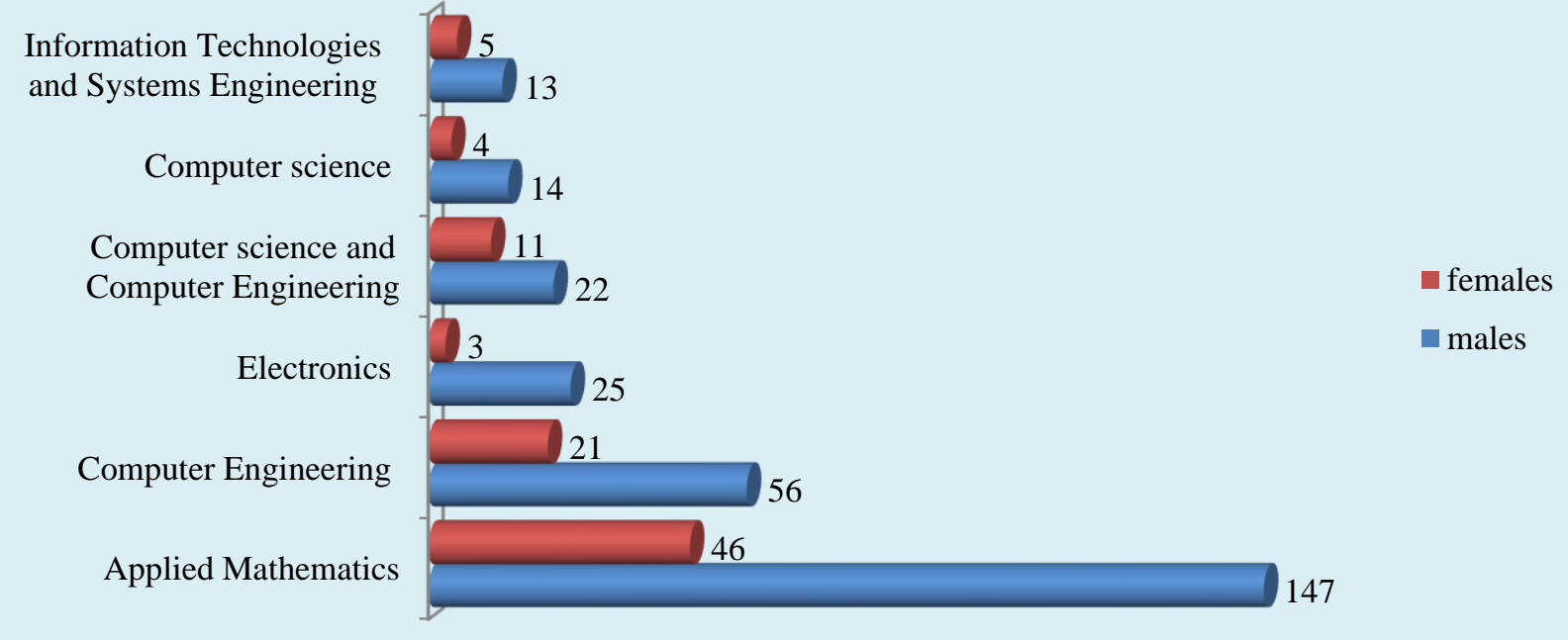

Figure 12. Quantitative distribution of graduates by the faculties

The graduates of these universities who have completed their studies in the years 2006-2015, are included here as employed or unemployed. A total of 367 people participated in the survey, about $25 \%$ of whom are women, and $75 \%$ - men (Figure 13 ).

Results of the study have brought some clarity in the situation. Analysis of the data of the sociological survey showed that nearly half of the graduates are not included in IT labor market (Figure 14). This data correlates with the results of surveys conducted by the companies Smart Start, Technopark Mail.Ru and HeadHunter among the IT-oriented students of a number of Moscow universities and working professionals, according to which $55 \%$ of experienced professionals, who participated in the survey, do not work on IT specialty, acquired in college. [25] 


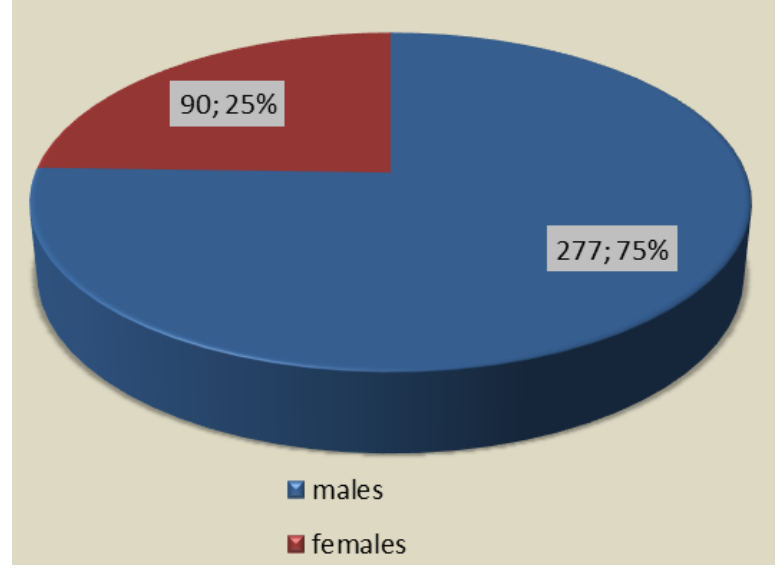

Figure 13. Distribution of the respondents by gender

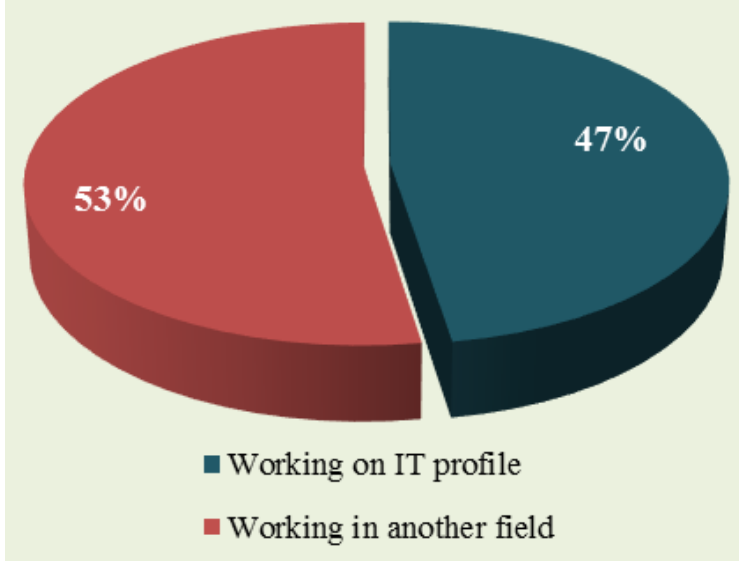

Figure 14. The proportion of those working as IT professionals in the total number of the graduates

According to the data (Figure 15), $46 \%$ of surveyed males do not work on their specialty. As the reasons for the transition to other areas, $22.3 \%$ of men indicate uncertainty about their IT skills, $31.8 \%$ - loss of IT qualifications after the army, $24.2 \%$ - higher salary in the business sector, $11.7 \%$ - discrimination by the employer.

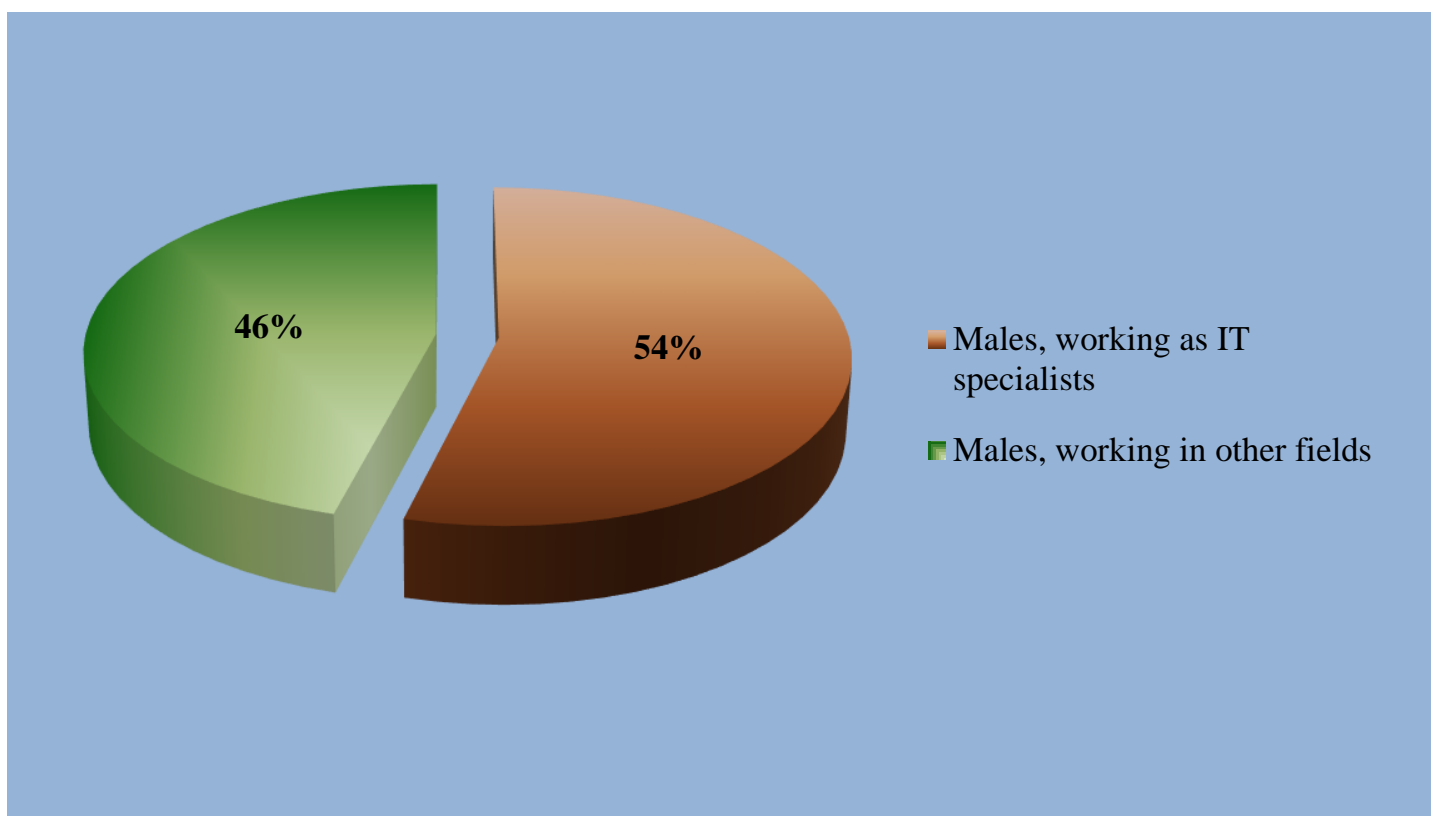

Figure 15. The share of males working on the IT profession in the total number of male graduates

Gender component of the study, which expressed enough, (Figure 16) is very interesting. Thus, $29.3 \%$ of women work on their specialty, $39.4 \%$ are engaged in the activities unrelated to obtained specialty, and $25 \%$ do not work at all after graduation. Among women working on their specialty, the largest share $-46.7 \%$ are accounted for the areas related to the design or layout, $32.3 \%$ teach computer science at secondary and post-secondary schools, $13.2 \%$ work in marketing, and remaining $8,7 \%$ are engaged in research activities. The choice of women working in these areas is explained by the absence of business trips, inflexible working hours and the ability to conveniently combine work with family. 
According to the survey, the predominant part of working women has changed the scope of activities. As the reasons for the transition to other areas $29.7 \%$ of women indicated the lack of confidence in their IT skills, 36.9\% - loss of IT qualifications after marriage and child care, 18.8\% higher salary in the business sector, $142 \%$-gender discrimination by the employer. $25 \%$ of women not working after the graduation relate this to the status of housewife with a family emergency.

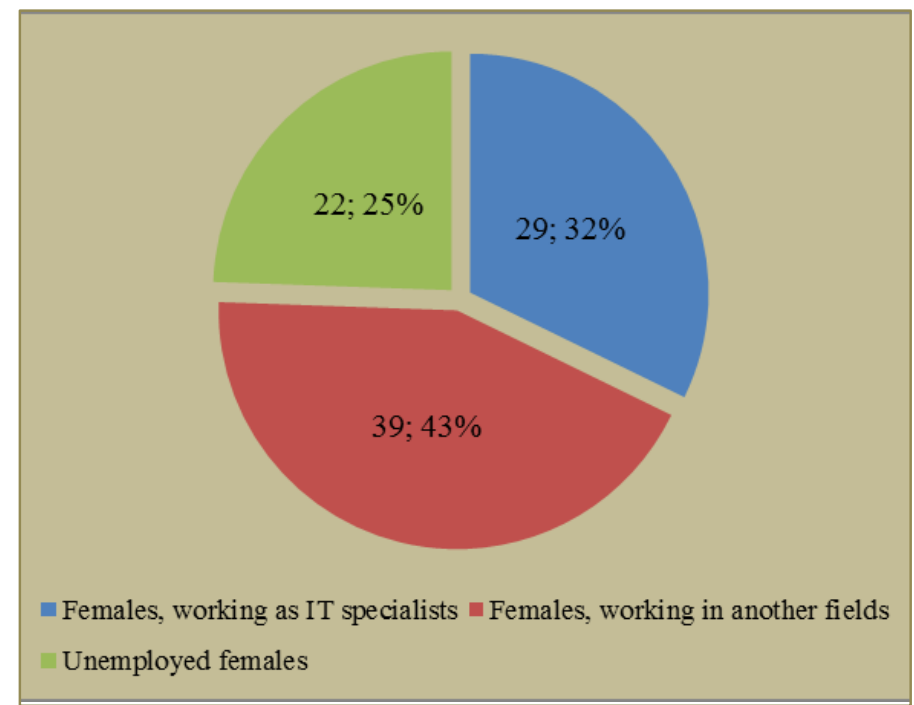

Figure 16. Distribution of women by their status in the labour market

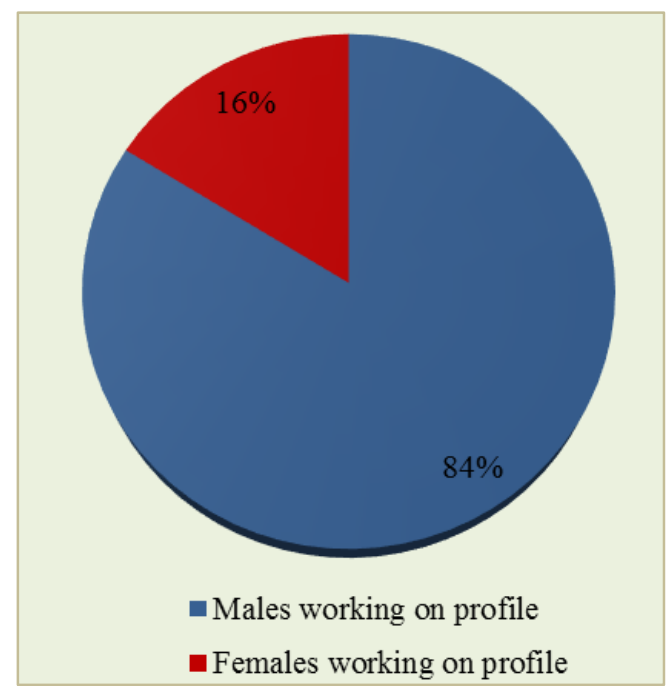

Figure 17. Distribution of men and women, with their status in the labor market working on their specialty

Figure 17 shows the distribution of men and women working on the specialty. In accordance with the percentage of IT staff by gender the data obtained is 5:1 in favor of men.

It should be noted that the gender problem in IT is important in all countries. However, increasing trend of demand for IT professionals greatly expands the opportunities for women in obtaining highly qualified employment in the IT industry [26]. This may be explained by the recent increase of the proportion of women in IT. Consequently, according to Eurostat data, the coefficient of male to female was 7: 1 in 2002 in euro area [27], while in 2015, this gap is reduced to about 5:1, 4:1 [28] depending on the country. However, a significant gap in the ratio between men and women in IT remained. Thus, our hypothesis regarding the significant outflow of IT professionals from the industry is confirmed. The result of this study shows an alarming trend in the labor market of IT-segment. Naturally, to make final conclusions about outflows of IT specialists in other fields of activity it is necessary to conduct a representative study.

\section{Conclusion}

Opinions and attitudes of respondents, reflecting the various aspects of IT personnel readiness of the labor market may be individually evaluated. However, we should take into account the fact that these estimations are based on sociological study, in accordance with a system of coherent methodological, methodical, organizational and technical procedures, and provide reliable information on various actors working in IT labor market and reflect the real situation regarding the relationship between the demand and supply in the labor market of IT segment of the economy of the country. 


\section{References}

1. E-Skills for Jobs in Europe. www.eskills2014.eu

2. Skill mismatch Identifying priorities for future research. Cedefop research arena. Thessaloniki, May 2009, 24 p. www.cedefop.europa.eu/en/Files/6103_en.pdf

3. European Vacancy Monitor (EVM). 2012. http://ec.europa.eu/social/main.jsp?catId=955\&langId=en

4. Wennergren D.M. Forecast of Future IT Labor Supply and Demand. U.S., 2007. http://dodcio.defense.gov/Home/Initiatives/NetGenerationGuide/ForecastofFutureLaborSup plyandDemand.aspx

5. Ticol D. Labour supply/demand dynamics of Canada's information and communications technology (ICT) sector. Final Report, 2012, 30 p.

6. Mammadova M.G., Jabrailova Z.G., Manafli M.I. Monitoring of demand for information technology specialists. Baku: Information Technology, 2009, 199 p.

7. IT frames 2010. The number of employment in the Russian economy in 2009 and the forecast for demand of the years 2010-2015 / Analytical Center REAL; Association for Computer and Information Technology. 2010.

www.apkit.ru/committees/education/projects/itcadry2010.php

8. IT-specialists deficit in 2015 will amount to 170 thousand people. UNIAN.

www.unian.net/society/871034-defitsit-it-spetsialistov-v-2015-godu-gosinformnauki.html

9. Development Concept "Azerbaijan 2020: Vision into the future" www.president.az/files/future_ru.pdf

10. Cattaneo, G., Kolding M., Lifonti R., Hüsing T., Korte W.B. Anticipating the development of the supply and demand of e-skills in Europe 2010-2015. Milan, Bonn: European Commission, 2009. http://ec.europa.eu/enterprise/sectors/ict/files/e-skills_foresight_scenarios_2015_en.pdf

11. Bartlett W. Skills anticipation and matching systems in transition and developing countries: conditions and challenges //Working paper for the European Training Foundation. www.etf.europa.eu/webatt.nsf/0/84E964F6CBD16532C1257AAD0038EC27/\$file/Skills.pdf

12. Forecast and anticipation for skills demand and supply in ETF partner countries // Working paper for the European Training Foundation, 2013. www.etf.europa.eu

13. Mammadova M., Mammadzadeh F. Formation of supply and demand for IT specialists on the base of competency model // IV International Conference Problems of Cybernetics and Informatics (PCI-2012), 12-14 Sept., 2012, Baku, 2012,vol. IV, pp. 199-201. doi:10.1109/icpci.2012.6486486

14. Research Study on High-Level Skill Needs in NI ICT Sector. Final Report. Oxford Economics, 2009, 129 p.

15. Mammadova M.G., Mammadzadeh F.R. Development of the conceptual foundations of intelligent control of supply and demand in the labor market of information technology specialists. East European Journal of advanced technologies, 2015, No 4/3 (76), pp. 53-67.

16. Department for Employment and Learning. Research Study on High-Level Skill Needs in NI ICT Sector. Final Report. Oxford Economics, 2009, 129 p. www.delni.gov.uk/research_study_on_high-level_skill_needs.pdf

17. National Strategy for the Development of Information Society in the Republic of Azerbaijan for 2014-2020. www.e-gov.ru/news/

18. Mammadova M.G., Mammadzadeh F.R. Object-oriented approach to the definition of the relevance of information technology education market with the demand in the IT specialists market. // Education and science. 2014, No 5, pp. 54-66.

19. Mammadova M.G., Mahmudov M.A., Mammadzadeh F.R. Azerbaijan: current issues and technologies for matching supply and demand in the labor market // Proceedings of VI International scientific-practical conference on "Actual problems of professional orientation and vocational training of the population", Kyiv, November 29-30, 2012, pp. 105-117. 
20. Mammadova M.G. Continuous vocational training in Azerbaijan // "Labor and social problems" - proceedings of RIC on Labor and Social Issues, 2012, Issue 2 (10), p.6-19.

21. Monitoring e-Skills Demand and Supply in Europe. The Evolution of the supply and demand e-skills in Europe" 2010.

http://ec.europa.eu/enterprise/sectors/ict/files/e_skills_supply_and_demand_en.pdf

22. ROA reports.

roa.sbe.maastrichtuniversity.nl/roanew/wp-content/uploads/2014/05/ROA_R_2014_5.pdf

23. Annual reports. www.skillsireland.ie/Publications/.

24. Mammadova M.G., Mammadzadeh F.R. Qualitative analysis of IT education in Azerbaijan from the supply and demand position // "Work and social problems" - proceedings of RIC on Labor and Social Issues, 2012, Issue 3 (11), pp.6-16.

25. More than half of IT professionals do not work on the specialty, acquired in college. https://corp.mail.ru/ru/press/releases/9137/

26. The gender aspect in the digital economy. Newsletter №3, 2016. www.hse.ru/data/2016/04/29/1128583015/\%D0\%9C\%D0\%BE\%D0\%BD\%D0\%B8\%D1\%8 2\%2016.pdf

27. Eurostat Year book 2004. The statistical guide to Europe Data 1992-2002. http://ec.europa.eu/eurostat/documents/3217494/5648861/KS-CD-04-001EN.PDF/05371ffe-c41c-4

28. Eurostat Year book 2015. http://ec.europa.eu/eurostat/documents/3217494/7018888/KS-HA15-001-EN-N.pdf/6f0d4095-5e7a-4aab-af28-d255e2bcb395 